\title{
The Influence of Short-term Physical Training Program on Female College Students
}

\author{
Liu Lihua ${ }^{1, \text { a }}$ \\ ${ }^{1}$ Institute of Disaster Prevention Science and Technology, Sanhe City 065201,China \\ aLiuLihua922@yeah.net
}

Keywords: Short-term physical training; Female students; Physical fitness; Analytic hierarchy process; Analysis of influence

\begin{abstract}
Good health is the basis of everyone's work and study. However, most college stude nts are trying to avoid sports training, especially in the female college students. The physical co nditions of them are not optimistic. This paper discusses the basic principle for short-term physi cal training. According to the survey, a short-term physical training program is proposed to imp rove physical conditions of female college students. We use analytic hierarchy process to analy ze the impact of short-term physical training on the physical fitness of female college students. We can obtain that short-term physical training can improve the physical fitness of female stude nts. It can also improve the ability to fight disease.
\end{abstract}

\section{Introduction}

The modern society is increasingly competitive and the pace of urban life is increasingly rapid. All the people are living a hard work. They spend most of their time and effort on learning and work [1]. The physical exercise is always being ignored or forgotten. For college female students, physical exercise is their troubles. Most of the female students are rarely participate in physical exercise, unless the necessary physical education. Secondly, most sports exercise facilities and venues of major college are set for boys. There are fewer sports facilities and venues for girls'. This is also one of reasons that the physical exercise time of female students is insufficient [2]. So the physical fitness of modern female students is worrying. After all, the increasingly fierce competition of modern society is the talent competition. In this article, we use analytic hierarchy process to analyze the impact of physical training on the physical fitness of female college students.

\section{The physical fitness synopsis of current female college students}

Currently, most college students' physical exercise was inadequate. In this paper, we used questionnaire to count and analyze the participation of university students in physical exercise. It included nine colleges and universities in the northern, central and southern of china which involved nine different levels of economic development cities. The results are shown in Table 1.

Table 1. The participation of exercise questionnaire of college students in teaching day and weekend

\begin{tabular}{c|c|c|c|c}
\hline \multirow{4}{*}{ Teaching day } & The total number & Male & Female & Total \\
\cline { 2 - 5 } & The exercise number & 1052 & 780 & 1832 \\
& Percentage & 86.4 & 67.9 & 77.4 \\
\multirow{4}{*}{ Weekend } & The total number & Male & Female & Total \\
& The exercise number & 970 & 635 & 1605 \\
& Percentage & 8305 & 54.4 & 65.3 \\
\hline
\end{tabular}


In Table 1, it can be seen that the number of people participate in physical exercise in the usual lectures day is more than the weekend. This suggests that many college students are only take part in physical exercise in class and they participate in physical exercise in their spare time is less [3]. At the same time, the survey results show that a considerable part of the college female students do not want to participate in physical exercise.

\section{Research steps}

The testers involved in one or two hours of training a week for 16 weeks. They first had 10 minutes warming up and carried out the main activities for 40 minutes (tensile, general and muscle strength training, stamina, agility and power). The recovery time lasted for 10 minutes. This training program started with low strength training, and then gradually continued high strength. In order to prevent injuries and be more familiar with test, they went through tests at the start before physical training program. The physical training program is shown in Table 2 .

Table 2. The short-term physical stamina training plan project table

\begin{tabular}{l|l|l}
\hline $\begin{array}{l}\text { Number } \\
1\end{array}$ & $\begin{array}{l}\text { Purpose of measurement } \\
\text { cardiopulmonary health }\end{array}$ & $\begin{array}{l}\text { Training project } \\
1600 \mathrm{~m} \text { walking and } \\
\text { running } \\
\text { proneness test } \\
3\end{array}$ \\
$\begin{array}{l}\text { flexibility } \\
\text { abdominal strength and } \\
\text { endurance } \\
\text { shoulder strength and } \\
\text { endurance } \\
\text { Muscle strength }\end{array}$ & $\begin{array}{l}\text { push-ups } \\
\text { vertical jump }\end{array}$ \\
\hline
\end{tabular}

\section{The basic principles and manners of the short-term physical training}

The process of physical training is the process that human body consumes the nutrient. This process follows the law of energy metabolism. In the process of body movement, it mainly consumes glucose, oxygen-free phosphonic acids and blood lactate etc. We use it to provide the energy consumption of body in physical training [4,5]. In this paper, we use blood lactate as an example to illustrate the basic principles of the short-term physical training as shown in Figure 3.
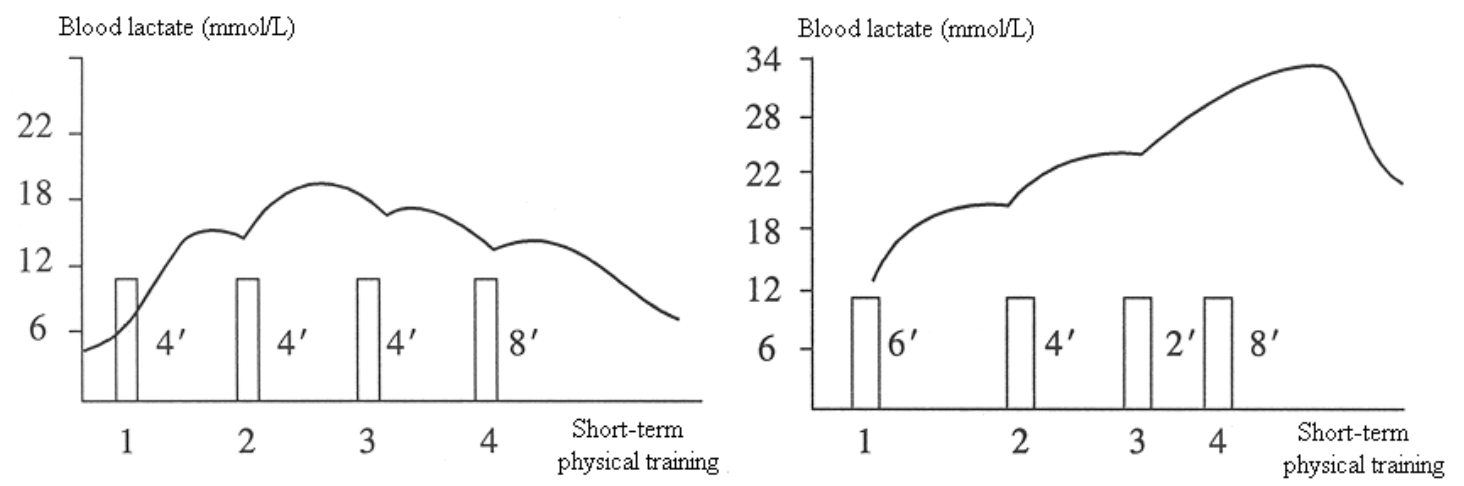

Figure 3. Schematic diagram of blood lactate consumption in short-term physical training

The short-term physical training is used to improve the motor function and physical fitness through the flexibility and durability exercise of the various parts of human body. This process need to exert some exercise load to the trainees when they are taking physical training. The body will consume energy to adapt to the stimulus when it is stimulated by external load. So the entire process can also be regarded as the energy consumption and recovery process. 


\section{The impact of physical training on the physical fitness of female college students based on analytic hierarchy process}

Assuming that the impact factors of physical training on the physical fitness of female college students is $U$. For each level of impact factors, there will be the next level influencing factors $u_{1}$. We can make it as $U=\left\{u_{1}, u_{2}, \ldots, u_{k}\right\}$, and it must meet $\cup U_{i=1}^{k}=U, U_{i} \cap U_{j}=\Phi$.

We can get the proportion value of all levels influencing factors through the calculation of the survey data results. So we can get the evaluation matrix of each level impact factors. The assessment results can be derived by the following formula $B=A \cdot R$. We can get the impact factors value of physical training on the physical fitness of female college students through the survey and calculation as shown in Table 4.

Table 4. Distribution table of the physical training impact factors on the physicalf itness of female college students

\begin{tabular}{c|c|c}
\hline First-level factors & Second-level factors & $\begin{array}{c}\text { Third-level } \\
\text { factors }\end{array}$ \\
Physical condition $u_{1}(0.45)$ & Emotional factors $u_{12}(1 / 3)$ & \\
& Menstrual period $u_{13}(1 / 3)$ & \\
Training intensity $u_{2}(0.2)$ & Indoor facilities $u_{31}(0.5)$ & \\
Training facilities $u_{3}(0.15)$ & Outdoor facilities $u_{32}(0.5)$ & \multirow{2}{*}{ Area $u_{421}(0.5)$} \\
external environment $u_{4}(0.2)$ & Weather conditions $u_{41}(0.4)$ & Shape $u_{422}(0.5)$ \\
\hline
\end{tabular}

We can see from Table 3, the impact factors of the physical training on the physical fitness of female college students can be divided into three. Namely:

The first-level: $U=\left\{u_{1}, u_{2}, u_{3}, u_{4}\right\}$;

The second level: $u_{1}=\left\{u_{11}, u_{12}, u_{13}\right\}, u_{3}=\left\{u_{31}, u_{32}\right\}, u_{4}=\left\{u_{41}, u_{42}\right\}$;

The third level: $u_{42}=\left\{u_{421}, u_{422}\right\}$;

The appraisal of factors influencing is done by level

(1) $U=\left\{u_{1}, u_{2}, u_{3}, u_{4}\right\}$

The proportion set is $A=\{0.45,0.2,0.15,0.2\}$. So the assessment results are:

$$
B=A \cdot R=A \cdot\left(\begin{array}{l}
B_{1} \\
B_{2} \\
B_{3} \\
B_{4}
\end{array}\right)=\left(\begin{array}{llll}
0.45 & 0.2 & 0.15 & 0.2
\end{array}\right) \cdot\left(\begin{array}{cccc}
0.901 & 0.825 & 0.78 & 0.662 \\
0.92 & 0.901 & 0.85 & 0.548 \\
0.87 & 0.921 & 0.754 & 0.813 \\
0.854 & 0.687 & 0.648 & 0.756
\end{array}\right)=(0.81,0.84,0.8,0.72)
$$

(2) $u_{1}=\left\{u_{11}, u_{12}, u_{13}\right\}$

The proportion set is $A_{1}=\{1 / 3,1 / 3,1 / 3\}$. So the assessment results are:

$$
B_{1}=A_{1} \cdot R_{1}=A_{1} \cdot\left(\begin{array}{l}
B_{11} \\
B_{21} \\
B_{31} \\
B_{41}
\end{array}\right)=\left(\begin{array}{lll}
1 / 3 & 1 / 3 & 1 / 3
\end{array}\right) \cdot\left(\begin{array}{ccc}
0.921 & 0.84 & 0.647 \\
0.824 & 0.645 & 0.725 \\
0.765 & 0.821 & 0.851
\end{array}\right)=(0.82,0.74,0.75,0.68)
$$

We can carry out the assessment of influencing factors to $u_{3}=\left\{u_{31}, u_{32}\right\}, u_{4}=\left\{u_{41}, u_{42}\right\}$, $u_{42}=\left\{u_{421}, u_{422}\right\}$ by turns. The results are shown in the following: Short-term physical training 
program can improve the heart and lung function of female students well. It can also improve lung capacity, blood pressure, pulse and other physiological indicators of female students. Meanwhile, it can also reduce the weight of the female students and make their body curves more perfectly. The most important thing is that short-term physical training can improve the ability of female students to fight disease. It can also improve the physical fitness of female students.

\section{Conclusions}

Physical fitness was an important aspect in the future competition of talent. A healthy body was a guarantee of success to study and work. According to the low conditions of female college students, the paper proposed that school and government should increase investment in the sports facilities and sports faculty of campus. We should carry out a variety of sports courses and sports activities, and guide students to actively participate in fitness activities. At the same time, college students should pay attention to their own health. They should not waste a lot of time on games and entertainment. They should participate in sports activities in schools, community organizations and class organizations regularly to maintain a healthy body.

\section{References}

[1] Po-Yu Chen, Joanna McKittrick, Marc André Meyers, "Biological materials: Functional adaptations and bioinspired designs", Progress in Materials Science, Vol. 57, No. 8, pp. 1492-1704, 2012.

[2] V. Racic, A. Pavic, J.M.W. Brownjohn, "Experimental identification and analytical modelling of human walking forces: Literature review", Journal of Sound and Vibration, Vol. 326, No. 1-2, pp. 1-49, 2009.

[3] Su Rui, Xun Ma, "The Impact of Title Event Sponsorship Announcements on Enterprise incomings Based on Background of China", AISS, Vol. 4, No. 19, pp. 438-442, 2012

[4] Lael Gershgoren, Gershon Tenenbaum, Aaron Gershgoren, Robert C. Eklund, "The effect of parental feedback on young athletes' perceived motivational climate, goal involvement, goal orientation, and performance", Psychology of Sport and Exercise, Vol. 12, No. 5, pp. 481-489, 2011.

[5] Mark H. Anshel, Norman L. Weatherby, Minsoo Kang, Tiffany Watson, "Rasch calibration of a unidimensional perfectionism inventory for sport", Psychology of Sport and Exercise, Vol. 10, No. 1, pp. 210-216, 2011. 